\title{
METHOD DEVELOPMENT, VALIDATION AND STABILITY STUDIES FOR DETERMINATION OF LURASIDONE HYDROCHLORIDE IN TABLET DOSAGE FORM BY RP-HPLC
}

\author{
BHAVANI THOTA, GEETHA SUSMITA ADEPU, RAJITHA GALLA*
}

Institute of Pharmaceutical Technology, Sri Padmavati Mahila Visvavidyalayam (Women's University), Tirupati-517502, Andhra Pradesh, India.

Email: rajitha_galla@yahoo.com

Received: 11 Jul 2018 Revised and Accepted: 13 Nov 2018

\section{ABSTRACT}

Objective: To develop a simple, rapid, sensitive, precise, accurate, economical and validated reverse phase high performance liquid chromatographic (RP-HPLC) method for the estimation of lurasidone hydrochloride in tablet dosage form.

Methods: The chromatographic separation was carried out on a prontosil C18, AQ (100 mm $\times 4.6 \mathrm{~mm}, 3 \mu \mathrm{m})$ column. A mixture of phosphate buffer $(\mathrm{pH} 3.0)$ : acetonitrile (ACN) $(55: 45 \mathrm{v} / \mathrm{v})$ was used as a mobile phase. Flow rate of $1.0 \mathrm{ml} / \mathrm{min}$ and $10 \mu \mathrm{l}$ injection volume was used for the assay. PDA detector was used, and the detection wavelength was $230 \mathrm{~nm}$. The retention time (RT) of lurasidone hydrochloride was found to be $4.505 \pm 0.01$ min. The method was validated according to the ICH guidelines.

Results: The calibration curve for lurasidone hydrochloride was linear with a correlation coefficient value 0.999 in the concentration range of 25 $125 \%$. Specificity, accuracy (\% mean recovery, 99.08\%), precision, detection limits, robustness (\% RSD $<2$ ) and system suitability were found to be within limits. Degradation studies were performed under different stressed conditions, and the results of degradation studies reveal that the developed method was stable.

Conclusion: The developed method was simple, reliable, economical and stable and it can be applied for the routine quality control analysis of lurasidone hydrochloride in tablet dosage forms.

Keywords: RP-HPLC, Lurasidone hydrochloride, Method validation, Forced degradation studies

(C) 2018 The Authors. Published by Innovare Academic Sciences Pvt Ltd. This is an open access article under the CC BY license (http://creativecommons.org/licenses/by/4.0/) DOI: http://dx.doi.org/10.22159/ijpps.2018v10i12.27895

\section{INTRODUCTION}

Lurasidone hydrochloride, chemically (3aR, 4S, 7R, 7aS)-2-\{(1R, 2R)-2[4-(1, 2benzisothiazol-3-yl) piperazin1ylmethyl] cyclohexylmethyl hexahydro-4, 7-methano-2H-isoindole-1, 3-dione is a potent antipsychotic drug belonging to the class of benzothiazole derivatives. It is used for the treatment of depressive episodes associated with bipolar I disorder (bipolar depression) in adults and also for the treatment of schizophrenia. Lurasidone hydrochloride is a white to offwhite crystalline powder, slightly soluble in water, ethanol, sparingly soluble in methanol, practically insoluble in $0.1 \mathrm{~N} \mathrm{HCl}$, toluene, and very slightly soluble in acetone. Lurasidone hydrochloride acts as an antagonist at Dopamine type-2 (D2) and 5-hydroxytryptamine (5HT2A) receptors. It also has moderate antagonistic activity at alpha $2 \mathrm{C}$-and alpha $2 \mathrm{~A}$-adrenergic receptors and is a partial agonist at 5HT1A receptors. This medication exhibits minimal or no affinity for histamine type-1 (H1) or muscarinic type-1 (M1) receptors.

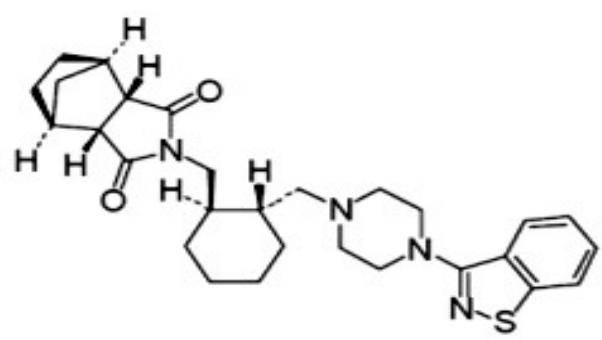

Fig. 1: Chemical structure of lurasidone

A survey of literature for the determination of lurasidone hydrochloride in pure and formulations revealed that various methods such as UV spectrophotometric [1-5], HPLC [6,7], RP-HPLC [8-11] methods and LC/MS/MS $[13,14]$ method for determining in rat plasma were available. However, some of these methods have certain drawbacks like longer run time, complexity in the composition of the mobile phase, a higher amount of buffer that can affect column performance and elution technique. It affects sensitivity, precision, and accuracy of the method. So, an attempt was made to develop simple, fast and validated RP-HPLC method for the estimation of lurasidone hydrochloride in pure and tablet dosage forms.

\section{MATERIALS AND METHODS}

\section{Instrumentation}

The chromatographic separation with good retention was carried on Shimadzu LC AHT 2010 HPLC system with a prontosil C18 column of dimensions $100 \mathrm{~mm} \times 4.6 \mathrm{~mm}$ and particle size $3 \mu \mathrm{m}$. Water alliance 2690 HPLC PDA detector with automatic injector was used for the method development.

\section{Chemicals and reagents}

The lurasidone hydrochloride standard was obtained as a gift sample from Orchid health care, and dosage form latuda of Sunovion Pharmaceuticals Inc was purchased from local market. HPLC grade acetonitrile and methanol were purchased from Merck. Analytical grade $\mathrm{HCl}, \mathrm{NaOH}$ and $\mathrm{H} 2 \mathrm{O} 2$ were purchased from Finar and Merck. Milli-Q water was obtained from millipore.

\section{HPLC conditions}

The mobile phase used was a combination of previously degassed phosphate buffer ( $\mathrm{pH} 3.0)$ and ACN in the ratio of 55:45. The elution mode was isocratic with a flow rate of $1.0 \mathrm{ml} / \mathrm{min}$. The volume of the sample injected was $10 \mu$ l. Column temperature was maintained at $30^{\circ} \mathrm{C}$. The analyte was quantified at $230 \mathrm{~nm}$. 


\section{Standard preparation}

An accurately weighed amount, $20 \mathrm{mg}$ of lurasidone hydrochloride was transferred into a $100 \mathrm{ml}$ volumetric flask. $70 \mathrm{ml}$ of diluent was added to it and sonicated. Then final volume was made with diluent to prepare the primary stock solution. From the above solution, serial dilutions were made with diluent to obtain $120 \mathrm{ppm}$ of lurasidone hydrochloride.

\section{Sample preparation for $20 \mathrm{mg}$ tablets $(120 \mathrm{ppm})$}

For the sample preparation, 12 tablets were grinded into fine powder, and an accurate weight equivalent to $20 \mathrm{mg}$ was transferred into a $100 \mathrm{ml}$ volumetric flask. $70 \mathrm{ml}$ of diluent was added to it and kept the volumetric flask on a rotary shaker for 15 min at 200 RPM. It was sonicated for $30 \mathrm{~min}$ with intermediate shaking and diluted to the volume with diluent and mixed to get a primary sample stock solution. $10 \mathrm{ml}$ of the above solution was centrifuged at 2500 RPM for $10 \mathrm{~min}$. Then the solution was filtered through $0.45 \mu \mathrm{m}$ poly tetra fluoro ethylene (PTFE) filter by discarding first $2 \mathrm{ml}$ of the filtrate. Then serial dilutions were made with diluent and mixed well to get $120 \mathrm{ppm}$ of the sample.

\section{Procedure for assay}

Six replicates of standard and sample were analyzed. $10 \mu \mathrm{l}$ of the blank, standard solution prepared from active pharmaceutical ingredient (API) and test solution prepared from formulation was injected into the HPLC. The chromatogram was recorded, and the lurasidone hydrochloride peak area was used for calculating the percentage purity.

\section{Method validation}

The proposed method was validated [15-19] for specificity, linearity, accuracy, precision, limit of detection (LOD), limit of quantification (LOQ), robustness and system suitability as per international conference on harmonization (ICH) guidelines.

\section{Specificity}

Specificity is the ability of the analytical method to assess the analyte even in the presence of components which may expect to be present in the sample. Blank, standard, sample and placebo solutions were prepared and injected into the HPLC system to check the interference and to establish specificity.

\section{Linearity}

Linearity is the ability of the method to produce test results which are directly proportional to the concentration of the analyte in the given sample. Solutions for linearity analysis were prepared from the stock solution of the working standard to obtain the solutions at $25 \%, 50 \%, 75 \%, 100 \%$, and $125 \%$. These solutions were analyzed by injecting $10 \mu \mathrm{l}$ into the HPLC system for 3 replicates.

\section{Accuracy}

Accuracy of the method reveals the degree of similarity between the true value and the mean analytical value. Percentage recovery was determined at three concentration levels, i.e. $50 \%, 100 \%$ and $150 \%$ of the known concentration of the drug for 3 replicates.

\section{Precision}

Six different standard solutions were prepared from the homogeneous sample and were analyzed using the proposed method over a short period of time by the same analyst, on the same equipment, on the same day. The assay results and relative standard deviation were calculated, which indicates the intraday precision of the method.

\section{Limit of detection and limit of quantification (LOD and LOQ)}

The detection limit of an individual analytical procedure is the lowest amount of analyte in a sample which can be detected but not quantified as an exact value. The quantification limit of an individual analytical procedure is the lowest amount of analyte in a sample which can be quantitatively determined. To determine LOD and LOQ, a series of solutions were injected, and the signal-to-noise ratio for each injection was calculated.

$$
\begin{gathered}
\text { LOD }=3.3 \times \frac{\text { Standard deviation of intercept }}{\text { Average of slope }} \\
\text { LOD }=3.3 \times \frac{59.16}{19308}=0.0101 \mu \mathrm{g} / \mathrm{ml} \\
\mathrm{LOQ}=10 \times \frac{\text { Standard deviation of intercept }}{\text { Average of slope }} \\
\mathrm{LOQ}=10 \times \frac{59.16}{19308}=0.0306 \mu \mathrm{g} / \mathrm{ml}
\end{gathered}
$$

\section{Robustness}

Robustness was performed to know the ability of the method to resist small changes in the analytical procedure, and it indicates the reliability of the method. To determine robustness, one set of analysis was carried out by using the same homogenous sample by making minor, but deliberate changes in the analytical procedure. The robustness of the method was determined by making slight changes in the chromatographic conditions, i.e. flow variation \pm 0.2 $\mathrm{ml} / \mathrm{min}(0.8$ and $1.2 \mathrm{ml} / \mathrm{min})$, temperature variation $\pm 5{ }^{\circ} \mathrm{C}$ variation $\left(25^{\circ} \mathrm{C}\right.$ and $\left.35{ }^{\circ} \mathrm{C}\right)$, variation in buffer $\mathrm{pH} \pm 0.2$ units $(\mathrm{pH}$ 2.8 and $\mathrm{pH} 3.2$ ). The system suitability parameters were evaluated.

\section{System suitability}

System suitability is generally performed to check whether the developed method suits the intended purpose or not. It can be demonstrated by injecting five replicates of standard stock solutions into HPLC system. For the preparation of the standard stock solution, an accurately weighed amount $20 \mathrm{mg}$ of lurasidone hydrochloride was transferred into a $100 \mathrm{ml}$ volumetric flask. 70 $\mathrm{ml}$ of diluent was added to it and sonicated. Then final volume was made with diluent to prepare the primary stock solution. From the above solution, serial dilutions were made with diluent to obtain $120 \mathrm{ppm}$ of lurasidone hydrochloride. $10 \mu \mathrm{l}$ of this prepared solution was injected five replicates into the HPLC system and the results obtained were used to express the system suitability of the developed method.

\section{Forced degradation studies}

Forced degradation studies were performed to determine the stability of lurasidone hydrochloride in tablet dosage form. The drug was subjected to oxidative, acidic, basic, photolytic, relative humidity (RH) and thermal stress conditions.

\section{Peroxide degradation studies}

To perform peroxide degradation studies, an accurate amount of tablet powder which was quantitatively equivalent to $20 \mathrm{mg}$ of lurasidone hydrochloride was taken in a $50 \mathrm{ml}$ volumetric flask. 5 $\mathrm{ml}$ of $6 \% \mathrm{H} 2 \mathrm{O} 2$ solution was added and kept in a water bath at 80 ${ }^{\circ} \mathrm{C}$ for $15 \mathrm{~min}$; then the volumetric flask was removed from the water bath and allowed to cool. $30 \mathrm{ml}$ of diluent was added, sonicated for $30 \mathrm{~min}$. The final volume was made with diluent. Then it was filtered through $0.45 \mu \mathrm{m}$ PTFE filter. Serial dilutions were made to obtain $120 \mathrm{ppm}$ concentration of lurasidone hydrochloride solution. From the resultant solution (12 0 ppm) 10 $\mu \mathrm{l}$ was injected into the HPLC system, and the chromatogram was recorded to assess the stability of the sample.

\section{Acid degradation studies}

Acid degradation studies were performed by weighing an accurate amount of tablet powder which was quantitatively equivalent to $20 \mathrm{mg}$ of lurasidone hydrochloride. This was taken in a $50 \mathrm{ml}$ volumetric flask. $5 \mathrm{ml}$ of $2 \mathrm{~N} \mathrm{HCl}$ was added and kept in a water bath at $80{ }^{\circ} \mathrm{C}$ for $2 \mathrm{~h}$. Then the volumetric flask was removed from the water bath, allowed to cool and $5 \mathrm{ml}$ of $2 \mathrm{~N}$ $\mathrm{NaOH}$ solution was added. $25 \mathrm{ml}$ of diluent was added and sonicated for $30 \mathrm{~min}$. Final volume was made with diluent. Then it was filtered through $0.45 \mu \mathrm{m}$ PTFE filter. Serial dilutions were made to obtain $120 \mathrm{ppm}$ concentration of lurasidone hydrochloride solution. $10 \mu \mathrm{l}$ from the resultant solution was injected into the HPLC system, and the chromatogram was recorded to assess the stability of the sample. 


\section{Alkali degradation studies}

Alkali degradation studies were performed by weighing an accurate amount of tablet powder which was quantitatively equivalent to 20 mg of lurasidone hydrochloride. This was taken in a50 ml volumetric flask. $5 \mathrm{ml}$ of $2 \mathrm{~N} \mathrm{NaOH}$ was added and kept in a water bath at $80{ }^{\circ} \mathrm{C}$ for $2 \mathrm{~h}$. Then the volumetric flask was removed from the water bath, allowed to cool and $5 \mathrm{ml}$ of $2 \mathrm{~N} \mathrm{HCl}$ solution was added. $25 \mathrm{ml}$ of diluent was added and sonicated for $30 \mathrm{~min}$.

Final volume was made. Then it was filtered through $0.45 \mu \mathrm{m}$ PTFE filter. Serial dilutions were made to obtain $120 \mathrm{ppm}$ concentration of lurasidone hydrochloride solution. $10 \mu \mathrm{l}$ of $120 \mathrm{ppm}$ solution was injected into the HPLC system, and the chromatogram was recorded to assess the stability of the sample.

\section{Photolytic condition}

To perform the Photolytic degradation study, an accurately weighed amount of the sample which was quantitatively equivalent to $20 \mathrm{mg}$ of lurasidone hydrochloride was taken on to a clean and dry petri dish. Then petri dish was placed in the photo-stability chamber for intensity at $200 \mathrm{~W} . \mathrm{hr} / \mathrm{m}^{2}$ for $6 \mathrm{~h}$. The dried sample was taken, and a solution of concentration $120 \mu \mathrm{g} / \mathrm{ml}$ was prepared with diluent. From the $120 \mathrm{ppm}$ solution, $10 \mu \mathrm{l}$ solution was injected into the HPLC system, and the chromatogram was recorded to assess the stability of the sample.

\section{Humidity condition}

To perform humidity degradation studies, the drug solution was exposed to $90 \% \mathrm{RH}$ for $10 \mathrm{~d}$. The solution was diluted to $120 \mu \mathrm{g} / \mathrm{ml}$ with diluent. From the resultant solution, $10 \mu \mathrm{l}$ solution was injected into the HPLC system, and the chromatogram was recorded to assess the stability of the sample.

\section{Thermolytic condition}

To perform thermal degradation study, an accurately weighed amount of the sample which was quantitatively equivalent to $20 \mathrm{mg}$ of lurasidone hydrochloride was taken on to a clean and dry petri dish, spread it throughout the plate and placed in an oven at $80{ }^{\circ} \mathrm{C}$ for $6 \mathrm{~h}$. The dried sample was taken, and a solution of concentration $120 \mu \mathrm{g} / \mathrm{ml}$ was prepared with diluent. For HPLC study, from the resultant solution, $10 \mu \mathrm{l}$ was injected into the system, and the chromatogram was recorded to assess the stability of the sample.

\section{RESULTS AND DISCUSSION}

The method has been developed after performing several trials. In each trial different column, mobile phase and various flow rates were selected. The suitable wavelength for quantization was determined and fixed. The runtime for every individual analysis was 10 min. Optimized chromatographic conditions were given in table 1 and chromatogram of the optimized method was shown in fig. 2 .

Table 1: Optimized chromatographic conditions

\begin{tabular}{lll}
\hline S. No. & Parameters & Optimized condition \\
\hline 1. & Mobile phase ratio & pH 3.0 phosphate buffer: ACN $(55: 45)$ \\
2. & Column Prontosil & C18, AQ $(100 \times 4.6 \mathrm{~mm}, 3 \mu)$ \\
3. & Flow rate $(\mathrm{ml} / \mathrm{min})$ & 1.0 \\
4. & Detector wavelength $(\mathrm{nm})$ & 230 \\
5. & Run time(min) & 10 \\
6. & Elution mode & Isocratic \\
7. & Column temperature ${ }^{\circ} \mathrm{C}$ & 30 \\
8. & Volume of injection $(\mu \mathrm{l})$ & 10 \\
\hline
\end{tabular}

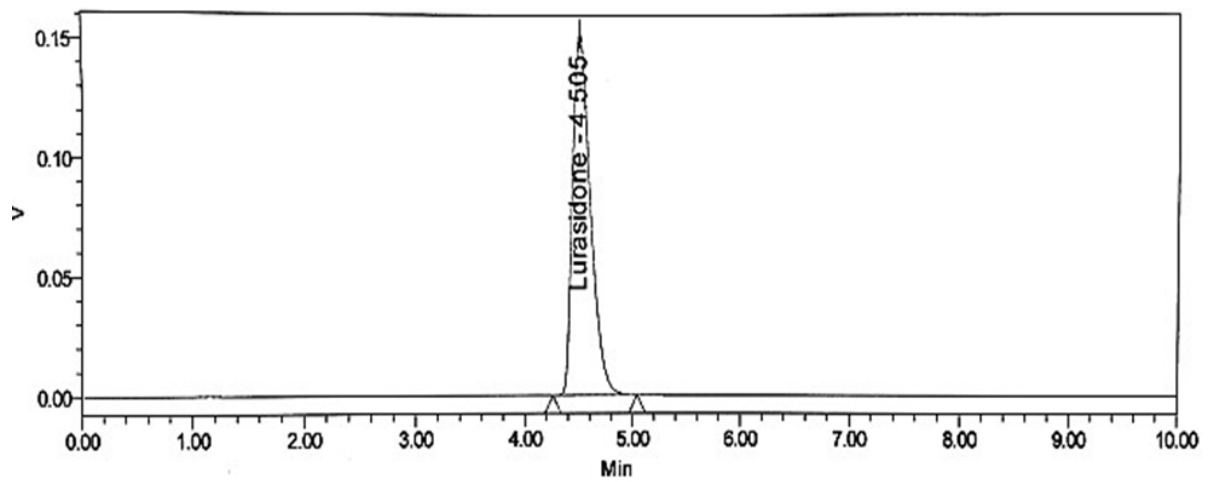

Fig. 2: Optimized chromatogram of standard lurasidone hydrochloride

\section{Specificity}

Specificity was carried out by injecting blank, placebo, standard and sample solutions individually into the HPLC system. Respective chromatographs were shown in fig. 3/fig. 3: Chromatograms for the specificity of lurasidone hydrochloride

\section{Linearity}

The linearity study of the lurasidone hydrochloride was carried out, and the calibration curves were found to be linear in the concentration range of $25-125 \mu \mathrm{g} / \mathrm{ml}$ with a regression coefficient of 0.999 . The equation of the regression line was $y=19308 x+5477$.
The linearity data and calibration plot for the lurasidone hydrochloride were given in the table 2 and fig. 4 respectively.

\section{Accuracy}

The percentage recovery and \% RSD were calculated. The mean percentage recovery of lurasidone hydrochloride (99.08\%) and \% RSD were found to be within limits (table 3).

\section{Precision}

The results of method precision were within limits. Method precision was performed within $24 \mathrm{~h}$ time lag and the \% RSD obtained for lurasidone hydrochloride was found to be $0.50 \%$ (table 4 ). 
Table 2: Linearity data for lurasidone hydrochloride

\begin{tabular}{|c|c|c|c|c|c|c|}
\hline S. No. & Sample name & Name & RT & Area & USP tailing & USP plate count \\
\hline 1 & Linearity-25\% & Lurasidone & 4.527 & 581454 & 1.43 & 3874 \\
\hline 2 & Linearity-50\% & Lurasidone & 4.515 & 1161124 & 1.48 & 3654 \\
\hline 3 & Linearity-75\% & Lurasidone & 4.505 & 1767554 & 1.53 & 3420 \\
\hline 4 & Linearity-100\% & Lurasidone & 4.497 & 2316224 & 1.56 & 3229 \\
\hline 5 & Linearity-125\% & Lurasidone & 4.481 & 3474416 & 1.61 & 2846 \\
\hline Mean* & & & & 1860154 & & \\
\hline Std. Dev & & & & 1111995.142 & & \\
\hline$\%$ RSD & & & & 59.8 & & \\
\hline
\end{tabular}

*Number of experiments-5, \% RSD: Relative standard deviation

Table 3: Recovery data for lurasidone hydrochloride

\begin{tabular}{|c|c|c|c|c|c|c|}
\hline $\begin{array}{l}\text { Concentration } \% \text { of the } \\
\text { spiked level }\end{array}$ & $\begin{array}{l}\text { Amount added } \\
\text { (mg) }\end{array}$ & $\begin{array}{l}\text { Amount found } \\
\text { (mg) }\end{array}$ & $\begin{array}{l}\text { Sample } \\
\text { area }\end{array}$ & $\begin{array}{l}\% \\
\text { Recovery }\end{array}$ & \multicolumn{2}{|c|}{$\begin{array}{l}\text { Statistical analysis of } \% \\
\text { recovery }\end{array}$} \\
\hline $50 \%$ Injection 1 & 360 & 359.97 & 1154224 & 98.90 & MEAN* & 98.86 \\
\hline $50 \%$ Injection 2 & 360 & 359.95 & 1154690 & 98.90 & $\%$ RSD & 0.05 \\
\hline $50 \%$ Injection 3 & 360 & 359.89 & 1153588 & 98.80 & & \\
\hline $100 \%$ Injection 1 & 720 & 720.06 & 2323511 & 100.00 & MEAN* & 99.87 \\
\hline $100 \%$ Injection 2 & 720 & 720.08 & 2324085 & 100.02 & \%RSD & 0.05 \\
\hline $100 \%$ Injection 3 & 720 & 719.96 & 2325635 & 99.60 & & \\
\hline $150 \%$ Injection 1 & 1080 & 1079.89 & 3427815 & 97.90 & MEAN* & 98.53 \\
\hline $150 \%$ Injection 2 & 1080 & 1079.94 & 3458067 & 98.80 & $\%$ RSD & 0.56 \\
\hline $150 \%$ Injection 3 & 1080 & 1079.98 & 3463586 & 98.90 & & \\
\hline
\end{tabular}

*Number of experiments-3, \% RSD: Relative standard deviation

Table 4: Method precision results for lurasidone hydrochloride

\begin{tabular}{|c|c|c|c|c|c|c|}
\hline S. No. & Sample name & Name & RT & Area & USP tailing & USP plate count \\
\hline 1 & Precision-1 & Lurasidone & 4.500 & 2293300 & 1.55 & 3178 \\
\hline 2 & Precision-2 & Lurasidone & 4.500 & 2292215 & 1.55 & 3188 \\
\hline 3 & Precision-3 & Lurasidone & 4.498 & 2288756 & 1.55 & 3183 \\
\hline 4 & Precision-4 & Lurasidone & 4.498 & 2270937 & 1.54 & 3194 \\
\hline 5 & Precision-5 & Lurasidone & 4.499 & 2270113 & 1.54 & 3181 \\
\hline 6 & Precision-6 & Lurasidone & 4.497 & 2270633 & 1.54 & 3186 \\
\hline Mean* & & & & 2280993 & & \\
\hline Std. Dev. & & & & 11528.014 & & \\
\hline$\%$ RSD & & & & 0.50 & & \\
\hline
\end{tabular}

*Number of experiments-6, \% RSD: Relative standard deviation

Table 5: LOD and LOQ data for lurasidone hydrochloride

\begin{tabular}{|c|c|c|}
\hline S. No. & The concentration of lurasidone hydrochloride $(\mu \mathrm{g} / \mathrm{ml})$ & Average peak area (response) \\
\hline 1 & 0 & 0 \\
\hline 2 & 30 & 581454 \\
\hline 3 & 60 & 1161124 \\
\hline 4 & 90 & 1767554 \\
\hline 5 & 120 & 2316224 \\
\hline 6 & 180 & 3474416 \\
\hline
\end{tabular}

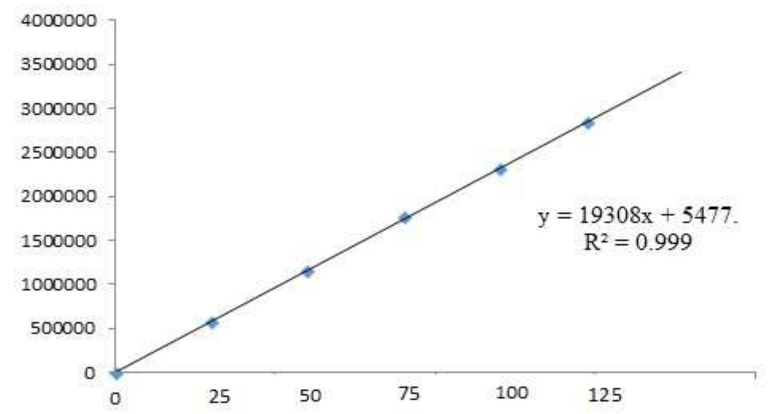

Fig. 4: Linearity plot of lurasidone hydrochloride

\section{LOD and LOQ}

LOD and LOQ were found to be $0.0101 \mu \mathrm{g} / \mathrm{ml}$ and $0.0306 \mu \mathrm{g} / \mathrm{ml}$ respectively. LOD and LOQ data were tabulated in table 5.

\section{Robustness}

Robustness was evaluated by making deliberate changes to the chromatographic parameters of the method. The obtained results (tables 6-9) indicated the minor changes in each condition did not affect the method and the system suitability parameters were found to be within limits.

\section{System suitability}

The system suitability parameters were evaluated from standard chromatograms obtained by calculating the \% RSD, retention time, tailing factor, theoretical plates and peak areas from five replicated injections. The tailing factor and theoretical plate count of lurasidone hydrochloride peak from first injection and \% RSD on replicating injections were recorded (table 10) and were found to be within the accepted criteria.

\section{Forced degradation studies}

In each condition of forced degradation studies, it was observed that the purity threshold value was found to be greater than the purity 
angle value and no purity flag was observed, which indicates that there was no interference of degradants with the analyte peak.
Degradation studies revealed that the developed method was stable. The results were incorporated in table 11.

Table 6: Data for robustness showing a change in temperature minus injections

\begin{tabular}{|c|c|c|c|c|c|c|}
\hline Injection No. & Sample name & Name & RT & Area & USP tailing & USP plate count \\
\hline 1 & Std-Column oven temp $\left(-5^{\circ} \mathrm{C}\right)$ & Lurasidone & 4.518 & 2308290 & 1.56 & 3275 \\
\hline 2 & Std-Column oven temp $\left(-5^{\circ} \mathrm{C}\right)$ & Lurasidone & 4.514 & 2310297 & 1.56 & 3263 \\
\hline 3 & Std-Column oven temp $\left(-5^{\circ} \mathrm{C}\right)$ & Lurasidone & 4.520 & 2311462 & 1.56 & 3282 \\
\hline 4 & Std-Column oven temp $\left(-5^{\circ} \mathrm{C}\right)$ & Lurasidone & 4.511 & 2313195 & 1.56 & 3237 \\
\hline 5 & Std-Column oven temp $\left(-5^{\circ} \mathrm{C}\right)$ & Lurasidone & 4.509 & 2312261 & 1.56 & 3234 \\
\hline Mean & & & & 2311101 & & \\
\hline Std. Dev. & & & & 1897.830 & & \\
\hline$\% \mathrm{RSD}^{*}$ & & & & 0.1 & & \\
\hline
\end{tabular}

${ }^{*}$ The $\%$ RSD was calculated from a mean of 5 replicate measurements, n-5.

Table 7: Data for robustness showing a change in temperature plus injections

\begin{tabular}{|c|c|c|c|c|c|c|}
\hline Injection No. & Sample name & Name & RT & Area & USP tailing & USP plate count \\
\hline 1 & Std-Column oven temp $\left(+5^{\circ} \mathrm{C}\right)$ & Lurasidone & 4.674 & 2347295 & 1.53 & 3261 \\
\hline 2 & Std-Column oven temp $\left(+5^{\circ} \mathrm{C}\right)$ & Lurasidone & 4.671 & 2346354 & 1.53 & 3256 \\
\hline 3 & Std-Column oven temp $\left(+5^{\circ} \mathrm{C}\right)$ & Lurasidone & 4.671 & 2348570 & 1.54 & 3256 \\
\hline 4 & Std-Column oven temp $\left(+5^{\circ} \mathrm{C}\right)$ & Lurasidone & 4.672 & 2348165 & 1.54 & 33259 \\
\hline 5 & Std-Column oven temp $\left(+5^{\circ} \mathrm{C}\right)$ & Lurasidone & 4.673 & 2347596 & 1.54 & 3257 \\
\hline Mean & & & & 2347596 & & \\
\hline Std. Dev & & & & 852.325 & & \\
\hline$\% \mathrm{RSD}^{*}$ & & & & 0.0 & & \\
\hline
\end{tabular}

*The \% RSD was calculated from a mean of 5 replicate measurements, n-5.

Table 8: Data for robustness showing a change in mobile phase pH minus (2.8)

\begin{tabular}{llllll}
\hline S. No. & Sample name & Peak name & RT & Area & USP tailing \\
\hline 1 & Standard (Low pH) & Lurasidone & 4.691 & 2323511 & 1.57 \\
2 & Standard (Low pH) & Lurasidone & 4.691 & 2324085 & 1.58 \\
3 & Standard (Low pH) & Lurasidone & 4.685 & 2325635 & 1.58 \\
Mean & & & & 2324410 & 3023 \\
Std. Dev & & & & 1098.74 & \\
\%RSD* & & & & 0.05 & \\
\hline
\end{tabular}

*The \% RSD was calculated from a mean of 3 replicate measurements, n-3.

Table 9: Data for robustness showing a change in mobile phase $\mathrm{pH}$ plus (3.2)

\begin{tabular}{|c|c|c|c|c|c|c|}
\hline S. No. & Sample name & Peak name & RT & Area & USP tailing & USP plate count \\
\hline 1 & Standard (High pH) & Lurasidone & 4.687 & 2327237 & 1.59 & 3042 \\
\hline 2 & Standard (High pH) & Lurasidone & 4.685 & 2328971 & 1.59 & 3037 \\
\hline 3 & Standard (High pH) & Lurasidone & 4.687 & 2527337 & 1.59 & 3054 \\
\hline Mean & & & & 2394515 & & \\
\hline Std. Dev & & & & 973.54 & & \\
\hline$\% \mathrm{RSD}^{*}$ & & & & 0.04 & & \\
\hline
\end{tabular}

*The \% RSD was calculated from a mean of 3 replicate measurements, n-3

Table 10: Data for system suitability

\begin{tabular}{llllll}
\hline S. No. & Name & RT & Area & USP tailing & USP plate count \\
\hline 1 & Lurasidone & 4.506 & 2321880 & 1.53 & 1.54 \\
2 & Lurasidone & 4.493 & 2318789 & 1.55 & 3113 \\
3 & Lurasidone & 4.491 & 2315816 & 1.56 & 3128 \\
4 & Lurasidone & 4.488 & 2316057 & 1.56 & 3139 \\
5 & Lurasidone & 4.484 & 2317289 & & \\
Mean* & & & 2317966 & & \\
Std. Dev. & & 2486.142 & & \\
\%RSD & & 0.1 & & \\
\hline
\end{tabular}

*The \% RSD was calculated from a mean of 5 replicate measurements, $n-5$, the results obtained in the method development and validation were found to be better and consistent when compared to other available methods. 
Table 11: Forced degradation studies data for lurasidone hydrochloride

\begin{tabular}{lllll}
\hline Mode of degradation & \multicolumn{2}{l}{ Lurasidone hydrochloride } & & Purity angle \\
\cline { 2 - 5 } & Area & \% Recovered & \% Degraded & Purity threshold \\
\hline Un degradation & 2451883 & - & - & 0.328 \\
Peroxide & 2487761 & 98.87 & 1.13 & 0.359 \\
Acid & 2451883 & 97.49 & 2.51 & 0.331 \\
Base & 2486395 & 98.76 & 1.24 & 0.348 \\
Photolytic & 2453780 & 97.57 & 2.43 & 0348 \\
Humidity & 2470186 & 98.19 & 1.81 & 0.334 \\
Thermal & 2459264 & 97.70 & 2.30 & 1.037 \\
\hline
\end{tabular}

\section{CONCLUSION}

The proposed reverse phase HPLC method was found to be simple, economical, precise, accurate and sensitive for the estimation of lurasidone hydrochloride in bulk and pharmaceutical dosage form. Degradation studies revealed that the developed method was stable. Hence, this method can easily and conveniently be adopted for routine quality control analysis of lurasidone hydrochloride pure and its pharmaceutical dosage forms.

\section{ACKNOWLEDGMENTS}

The authors are grateful to acknowledge ORCHID HEALTH CARE, a division of Orchid Pharma Ltd, Irugattukottai for providing facilities.

\section{AUTHORS CONTRIBUTIONS}

All the authors have contributed equally.

\section{CONFLICTS OF INTERESTS}

All authors have none to declare

\section{REFERENCES}

1. Vijaya Sri K, Sravani S, Shiva Kumar M. Development and validation of UV spectrophotometric method for estimation of lurasidone hydrochloride in bulk and pharmaceutical formulations. Asian J Pharm Res 2015;5:102-7.

2. Mali Nikita, Patel Jignesh, Patel Mandev. Validated spectrophotometric methods for the estimation of lurasidone hydrochloride in bulk and pharmaceutical dosage forms. Int J Res Pharma Sci 2012;2:44-50.

3. Muvvala S, Ratnakaram V. Simple and validated an ultraviolet spectrophotometric method for the estimation of lurasidone in bulk form. Res J Pharm Bio 2013;4:609-17.

4. Nirav K Joshi, Nehal Shah, Minaxi Dumasiya, Alisha Patel. Development and validation of spectrophotometric method for estimation of lurasidone hydrochloride: a novel antipsychotic drug in bulk and pharmaceutical dosage form. Int J Pharm Sci 2012;3:2643-53.

5. Ravishankar P, Rajyalakshmi G, Devadasu Ch, DevalaRao G. Validated UV spectrophotometric method for quantitative analysis of lurasidone hydrochloride in the pharmaceutical dosage form. Der Pharm Sin 2014;5:1-7.

6. Balaji M, Srinivasarao V, Appa Rao KM. Ch. Development and validation of stability are indicating a method for determination of Lurasidone in bulk drug and pharmaceutical dosage form by HPLC. Int J Pharm RD 2013;5:103-14.

7. Pawanjeet J Chhabd. Development and validation of stability indicating a method for determination of Lurasidone in bulk drug and pharmaceutical dosage form by HPLC. Int J Pharm RD 2013;5:103-14.

8. Madhulatha J, Ratnakar Cherukupally. RP-HPLC method development and validation for the estimation of lurasidone in the pharmaceutical dosage form. Int J Curr Res Health Bio Sci 2016;1:327-32.

9. Polawar AR, Damle MC. Development and validation of an RPHPLC method for estimation of lurasidone hydrochloride in bulk and pharmaceutical dosage form. Int J Res Pharm Chem 2014;4:327-32.

10. Bandala Koteswara Rao, Golkonda Ramu, Prameela Rani PNVVL, Chintala Rambabu. Assay of lurasidone by a stability indicating RP-HPLC method. Am J Pharm Tech Res 2014;4:449-68.

11. Suneetha A, Manasa K, Lakshmi Sindhura S. Stability indicating reverse phase high performance liquid chromatographic (RPHPLC) method for the analysis of lurasidone $\mathrm{HCl}$ in bulk and its tablet dosage forms. J Pharm Res 2015;14:15-9.

12. Rapilane Krishnamurthi Sangeetha. Method development and validation for the estimation of lurasidone by RP-HPLC and HPTLC. Eur J Pharm Med Res 2015;2:529-40.

13. Yoon Jee Chae, Tae Sung Koo, Kyeong Ryoon Lee. A sensitive and selective LC-MS method for the determination of lurasidone in rat plasma, bile, and urine. Chromatographia 2012;75:1117-28.

14. Tae Sung Koo, Soo Jin Kim, Jongjoo Lee, Dong Jin Ha, Myoungki Baek, Hongsik Moon. Quantification of lurasidone, an atypical antipsychotic drug, in rat plasma with high-performance liquid chromatography with tandem mass spectrometer. Biomed Chromatography 2011;25:1389-94.

15. Kachhawah SS, Biswal B, Anurekha Jain. Method development and validation for the simultaneous estimation of ascorbic acid and folic acid vitamins by reverse-phase high-performance liquid chromatography method in cyanobacterial metabolites and nutraceutical formulation. Asian J Pharm Clin Res 2016;9:353-5.

16. Shakir Basha S, Sravanthi P. Development and validation of dapagliflozin by reversed-phase high-performance liquid chromatography method and its forced degradation studies. Asian J Pharm Clin Res 2017;10:101-5.

17. Chandana OSS, Sathis Kumar D, Ravichandra Babu R. Method development and validation of eprosartan mesylate and its impurities using reverse-phase high-performance liquid chromatography. Int J Curr Pharm Res 2016;8:49-53.

18. Sultana Shaikh, Vandana Jain. Development and validation of novel RP-HPLC method for simultaneous estimation of gabapentin and amitriptyline hydrochloride in bulk and pharmaceutical dosage forms. Int J Appl Pharm 2018;10:97-104.

19. Paras Virani, Rajanit Sojitra, Hasumati Raj, Vineet Jain. Chromatographic method for irbesartan and its combination with other drug. J Crit Rev 2015;2:7-11. 